\title{
Elements of a single MAP kinase cascade in Saccharomyces cerevisiae mediate two developmental programs in the same cell type: mating and invasive growth
}

\author{
Radclyffe L. Roberts and Gerald R. Fink \\ Whitehead Institute for Biomedical Research and Department of Biology, Massachusetts Institute of Technology, Cambridge, \\ Massachusetts 02142 USA
}

\begin{abstract}
Diploid Saccharomyces cerevisiae strains starved for nitrogen undergo a developmental transition from a colonial form of growth to a filamentous pseudohyphal form. This dimorphism requires a polar budding pattern and elements of the MAP kinase signal transduction pathway essential for mating pheromone response in haploids. We report here that haploid strains exhibit an invasive growth behavior with many similarities to pseudohyphal development, including filament formation and agar penetration. Haploid filament formation depends on a switch from an axial to a bipolar mode of bud site selection. Filament formation is distinct from agar penetration in both haploids and diploids. We find that the same components of the MAP kinase cascade necessary for diploid pseudohyphal development (STE20, STE11, STE7, and STE12) are also required for both filament formation and agar penetration in haploids. Thus, haploid yeast cells can enter either of two developmental pathways: mating or invasive growth, both of which depend on elements of a single MAP kinase cascade. Our results provide a novel developmental model to study the dynamics of signal transduction, with implications for higher eukaryotes.
\end{abstract}

[Key Words: Signal transduction; MAP kinase; fungal dimorphism; budding]

Received August 31, 1994; revised version accepted October 18, 1994.

Mitogen-activated protein kinase (MAPK or ERK) signal transduction pathways are critical for many developmental events in eukaryotes, and require the sequential activation and phosphorylation of a series of protein kinases (for review, see Blumer and Johnson 1994). Activation of MAPK requires phosphorylation by activated MAPK/ERK kinase (MEK or MAPKK) (Crews et al. 1992). MEK activation is achieved by phosphorylation by RAFl or MEK kinase (MEKK or MAPKKK) (Kyriakis et al. 1992; Lange-Carter et al. 1993). Homologs of each of these components have been identified in a large number of eukaryotes. In the nematode Caenorhabdtis elegans, vulval induction requires signaling through the MAPK homolog Sur1/Mpk1 (Lackner et al. 1994; Wu and Han 1994). In Drosophila melanogaster, the MAPK homolog rolled is critical for photoreceptor development and dorsoventral patterning during embryogenesis (Brunner et al. 1994). In mammalian cells, MAPKs are important in a wide array of cytokine and growth factor responses (Pazin and Williams 1992; Schlessinger and Ullrich 1992; Foster 1993).

In the yeast Saccharomyces cerevisiae, several independent MAP kinase pathways have been characterized. One pathway mediates the response to hyperosmotic conditions through the MAP kinase pathway homologs
PBS2 (MEK) and HOG1 (MAPK), which stimulate glycerol accumulation (Brewster et al. 1993). A second pathway controls cell wall biosynthesis through $P K C 1$ (a protein kinase $\subseteq$ homolog) and the protein kinases $B C K 1$ (MEKK), MKK1 and $M K K 2$ (MEK), and MPK1 (MAPK) (Blumer and Johnson 1994). The best defined MAP kinase pathway controls the mating of haploid cells through STE11 (MEKK), STE7 (MEK), and FUS3 and KSS1 (MAPK).

In $S$. cerevisiae haploid cells, mating is triggered by pheromones and leads to the fusion of two cells of opposite mating type to form a diploid. The primary signaling event in this pathway, the binding of the peptide pheromone to its cognate receptor (Ste2p in MATa cells and Ste $3 p$ in $M A T \alpha$ cells), results in GDP/GTP exchange on the $\alpha$ subunit (Gpalp) of a heterotrimeric $\mathrm{G}$ protein (Dietzel and Kurjan 1987). The $\beta$ (Ste4p) and $\gamma$ (Ste18p) subunits then stimulate the activation of a series of protein kinases (Whiteway et al. 1989). Ste20p is proposed to link the $G$ protein to the kinase cascade (Leberer et al. 1992; Ramer and Davis 1993|. The MEKK homolog Ste11p (Rhodes et al. 1990; Stevenson et al. 1992) and the MEK homolog Ste7p are sequentially activated /Cairns et al. 19921, and the latter phosphorylates the MAPK homologs Fus3p and Ksslp (Gartner et al. 1992; Zhou et al. 
1993), which are partially redundant for mating functions (Elion et al. 1991a,b). Ste5p is thought to nucleate the assembly of the Ste1lp, Ste7p, and Fus3p protein kinases into a complex (Choi et al. 1994; Kranz et al. 1994; Marcus et al. 1994), which phosphorylates the transcription factor Ste12p (Elion et al. 1993). Fus3p also phosphorylates the cyclin-dependent kinase inhibitor Farlp (Elion et al. 1993), which mediates cell cycle arrest (Chang and Herskowitz 1990). Stel2p activates the transcription of mating-specific genes including FUS1 (Dolan and Fields 1990) and genes linked to the transposon Ty (Van Arsdell et al. 1987; Ciriacy et al. 1991). Thus, activation of the MAP kinase pathway in two haploid cells of opposite mating type arrests vegetative growth and leads to the fusion of the two cells to form a diploid.

Elements of the mating pheromone response MAP kinase pathway are also essential for pseudohyphal development in diploid strains (Liu et al. 1993). When starved for nitrogen, diploid cells undergo a developmental transition from a single cell yeast form to a filamentous pseudohyphal form. Pseudohyphal filaments are composed of chains of long thin cells that radiate away from the colony and penetrate the agar substrate on which they are grown (Gimeno et al. 1992). Mutations in STE20, STE11, STE7, or STE12 block the filament formation, cell elongation, and agar penetration of pseudohyphal cells. However, mutations in the pheromone receptors and G protein do not affect pseudohyphal development, suggesting that other molecules generate and transduce the signal that triggers filamentous growth (Liu et al. 1993).

The finding that both mating and filamentous growth use elements of the same MAP kinase cascade raises the question of how the same signal transduction pathway can specify two different developmental sequences. Specifically, the Ste12p transcription factor must activate mating-specific genes in the haploid and pseudohyphalspecific genes in the diploid. In one model, stimulation of the MAP kinase cascade in haploid MATa or MAT $\alpha$ cells results in the activation of mating-specific events, whereas stimulation of this pathway in diploid MATa $/ \alpha$ cells results in pseudohyphal development. According to this model, factors specific to each cell type determine the ensemble of genes that are regulated by Ste12p. For example, al and $\alpha 2$ may repress the activation of matingspecific genes, such as FUS1, in the MATa/ $\alpha$ diploid cell, allowing the induction of genes specific to filamentous growth under conditions of nitrogen starvation.

In addition to elements of the mating MAP kinase cascade, filament formation also requires a series of polarized cell divisions determined by the site of bud emergence of each new cell in the growing chain. Diploid cells bud in the bipolar mode, where the first bud of a virgin mother emerges from the free end of the cell and subsequent buds emerge from either the birth or free end of the cell (Freifelder 1960). The birth end is defined as the region where each cell is attached to its mother; the opposite end is the free end (Freifelder 1960). Pseudohyphal cells bud in a unipolar mode rather than the bipolar mode typical of diploid yeast form cells (Kron et al.
1994). In the unipolar mode, the first bud and all subsequent buds emerge from the free end of the cell. Successive rounds of unipolar budding produce a chain of first daughters oriented away from the cell that initiated the chain. In contrast, most haploid cells bud in an axial mode of bud site selection and do not form filaments readily when starved for nitrogen (Gimeno et al. 1992). In the axial mode, each new bud emerges from the birth end of a cell (Freifelder 1960). Successive rounds of axial budding produce a cluster of cells rather than the ordered chain of cells required to form a filament (Gimeno and Fink 1992). The bud site selection mode is determined by a regulatory cascade of $B U D$ genes $($ Chant and Herskowitz 1991). A mutation in BUD1 (RSR1) disrupts the bipolar budding pattern of diploids (Bender and Pringle 1989) and drastically reduces their ability to form filaments (Gimeno et al. 1992).

In this paper we describe a haploid invasive growth behavior with several similarities to diploid pseudohyphal development. Specifically, haploids switch their pattern of bud site selection from an axial to a bipolar pattern and consequently form filaments. In addition, they penetrate the agar substrate on which they are grown. Haploid filament formation and agar penetration depend on the same pheromone response MAP kinase cascade components required for diploid pseudohyphal growth. Thus, in a single cell the same signal transduction pathway can mediate two distinct developmental sequences showing that the differential outputs of the pathway do not require cell type-specific factors.

\section{Results}

Haploid cells are capable of agar penetration and filament formation on rich medium

MATa and MAT $\alpha$ haploid strains of the $\Sigma 1278 \mathrm{~b}$ background grown on rich medium plates (YPD) for several days begin to penetrate the agar beneath each colony (Fig. 1; Table 1). A population of cells that have penetrated the agar can be observed by washing the top portion of the colony off of the agar surface with water. The remaining cells are judged to have penetrated the agar surface because they are inaccessible to a microdissection needle unless the needle pierces the agar. After 3 days of growth, when the mass of cells on top of the agar has already slowed its growth, the number of cells that have penetrated the agar increases steadily, suggesting that agar penetration may be triggered by nutrient limitation. However, haploid agar penetration may not be related to ammonia deprivation because the addition of ammonium sulfate to YPD does not diminish agar penetration. Remarkably, isogenic MATa/ $\alpha$ diploid cells do not penetrate agar efficiently under these conditions, except after extremely long incubations, and the few cells that remain in the agar have the yeast form (Fig. 1).

The haploid cells remaining in the agar after washing the plate form networks of filaments underneath each colony (Fig. 2). The cells of these haploid filaments are not as elongated as those observed in diploid filaments, 
Figure 1. Invasive growth of haploid strains. Haploid MAT (L5487) and MATa (L5528) strains were patched on YPD with an isogenic diploid MATa/ $\alpha$ strain (L5721) and incubated as described in Materials and methods. The plate was photographed before (total growth) and after (invasive growth) washing the cells off of the agar surface.
Total growth

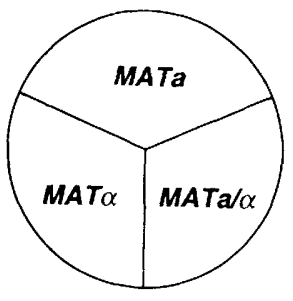

Invasive growth

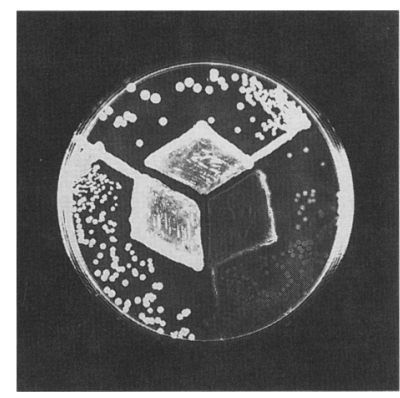

although some may have a slightly greater length-towidth ratio than they do during exponential growth (1.43 \pm 0.02 as compared with $1.07 \pm 0.01$ ) (mean \pm S.E.M.). Even after prolonged incubations, these haploid filaments do not extend beyond the perimeter of the colony but are restricted to the agar immediately beneath it. Thus, we define the combination of filament formation and agar penetration that occurs underneath each colony on rich medium as haploid invasive growth.

\section{Bud site switching during haploid invasive growth}

Haploid filament formation is unexpected because haploid cells bud in the axial mode, a pattern inconsistent with filament formation. Even if the cells fail to separate after cytokinesis, reiteration of this budding pattern produces clumps of cells, not the sequential extensions required for filament formation (Fig. 2). To determine the growth pattern of our strains, we compared the budding pattern of cells during exponential and invasive growth by staining their bud scars with calcofluor, a fluorescent compound that binds the chitin ring at the motherdaughter junction.

Cells were divided into three classes based on the distribution of their bud scars: axial, bipolar, and anomalous (see Materials and methods). Haploid cells in exponential phase either on plates or in liquid bud in a very strict axial mode, where all the bud scars are clustered together at one end of the cell (Fig. 3; Table 2). Even after extended growth periods in liquid medium, these cells continue to bud in an axial mode (Table 3). Remarkably,

Table 1. Strains used in this study

\begin{tabular}{lll}
\hline Strain & Genotype & Source \\
\hline L5528 & MATa, ura3-52, his3::hisG & this study \\
L5487 & MATa, ura3-52, leu2::hisG & this study \\
L5466 & MATa, ste2::LEU2, ura3-52, leu2::hisG & Liu et al. (1994) \\
L5549 & MATa, ste4::LEU2, ura3-52, leu2::hisG & Liu et al. (1994) \\
L5579 & MATa, ste18::LEU2, ura3-52, leu2::hisG & Liu et al. (1994) \\
L5585 & MATa, ste20::TRP1, ura3-52, trp1::hisG & Liu et al. (1994) \\
L5554 & MATa, ste5::LEU2, ura3-52, leu2::hisG & Liu et al. (1994) \\
L5565 & MATa, ste11::URA3::TRP1, ura3-52, trp1::hisG & Liu et al. (1994) \\
L5559 & MATa, ste7::LEU2, ura3-52, leu2::hisG & Liu et al. (1994) \\
L5743 & MATa, fus3::LEU2, ura3-52, leu2::hisG & Liu et al. (1994) \\
L5491 & MATa, kss1:URA3::LEU2, ura3-52, leu2::hisG & Liu et al. (1994) \\
L5722 & MATa, fus3::LEU2, kss1::URA3::LEU2, ura3-52, leu2::hisG & this study \\
L5723 & $\quad$ fus3::LEU2, ste7::LEU2, ura3-52, leu2::hisG & this study \\
L5724 & fus3::LEU2, ste12::LEU2, ura3-52, leu2::hisG & this study \\
L5573 & MATa, ste12::LEU2, ura3-52, leu2::hisG & Liu et al. (1994) \\
L5742 & MATa, far1::URA3, ura3-52, his3::hisG & this study \\
L5721 & MATa/ $\alpha$, ura3-52/ura3-52, his3::hisG/HIS3, leu2::hisG/LEU2 & this study \\
L5729 & MATa/ $\alpha$, bud1::URA3/bud1::URA3 ura3-52/ura3-52, his3::hisG/HIS3, leu2::hisG/LEU2 & this study \\
L5741 & MATa/ $\alpha$, ste12::LEU2/STE12, leu2::hisG/leu2::hisG & this study \\
L5726 & MATa, bud1::URA3, ura3-52, his3::hisG & this study \\
L5727 & MATa, bud2::LEU2, ura3-52, leu2::hisG & this study \\
L5725 & MATa, bud3::URA3, ura3-52, his3::hisG & this study \\
F1432 & MATa, bud4, ura3-52 & Gimeno and Fink (1994) \\
L5740 & MATa, bud5::URA3, ura3-52, his3::hisG & this study \\
L5728 & MATa, ura3-52, his3::hisG, ura3::FUS1-lacZ-URA3 & this study \\
\hline
\end{tabular}

All strains are congenic to the $\Sigma 1278$ b genetic background (Grenson et al. 1966; Liu et al. 1993). 

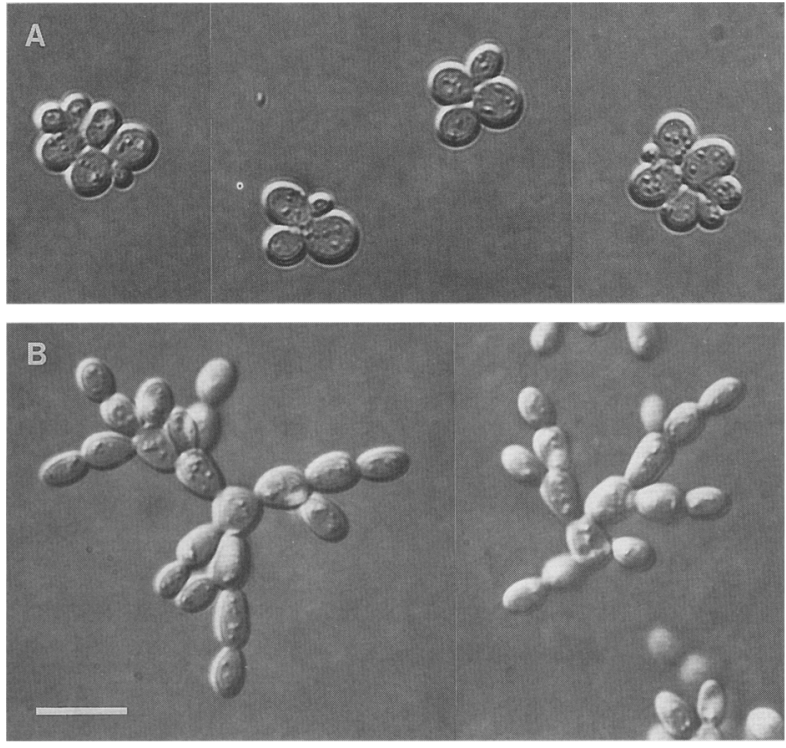

Figure 2. Filament formation during haploid invasive growth. The haploid MATa strain L5528 was photographed during exponential growth in YPD liquid $(A)$ and during invasive growth in a YPD plate $(B)$. Bar, $10 \mu$.

invasive haploid cells from washed plates exhibit a bipolar pattern of bud scar distribution, with scars clustered at both ends of the cell. The frequency and appearance of these bipolar haploids is comparable to that of diploids in the yeast form (Fig. 3; Table 2). Cells in the population that do not manifest the bipolar pattern could be either cells in the axial mode that have not switched or cells that have switched but are in the unipolar pattern rather than the bipolar pattern (Kron et al. 1994). Because the distribution of bud scars is the same for cells dividing in the axial and unipolar patterns, these two modes could not be distinguished by this method.

The finding that haploid cells can switch from axial to bipolar budding on plates suggested that this switch is critical for filament formation. To determine directly whether the cells in haploid filaments have the diploid cell division motif, we recorded the growth of filaments in the plate by time-lapse photography. In a high proportion of the cells in haploid filaments $(52 / 70)$, the first bud of a virgin mother emerges from the free end of the cell. This pattern, typical of bipolar budding in diploid strains, permits the formation of filaments through a series of polarized cell divisions. The bipolar pattern contrasts with that of haploids in exponential growth, where all new buds emerge from the birth end of the cell $178 /$ 78). The bipolar cells are not diploids because, when excised from the agar, they give rise to cells capable of mating with cells of the appropriate mating type. Thus, haploids grown on plates can switch their budding pattern from an axial to a bipolar mode and form filaments. This switch demonstrates that bud site selection is not a fixed parameter determined by cell type but, rather, a dynamic process sensitive to environmental influences.
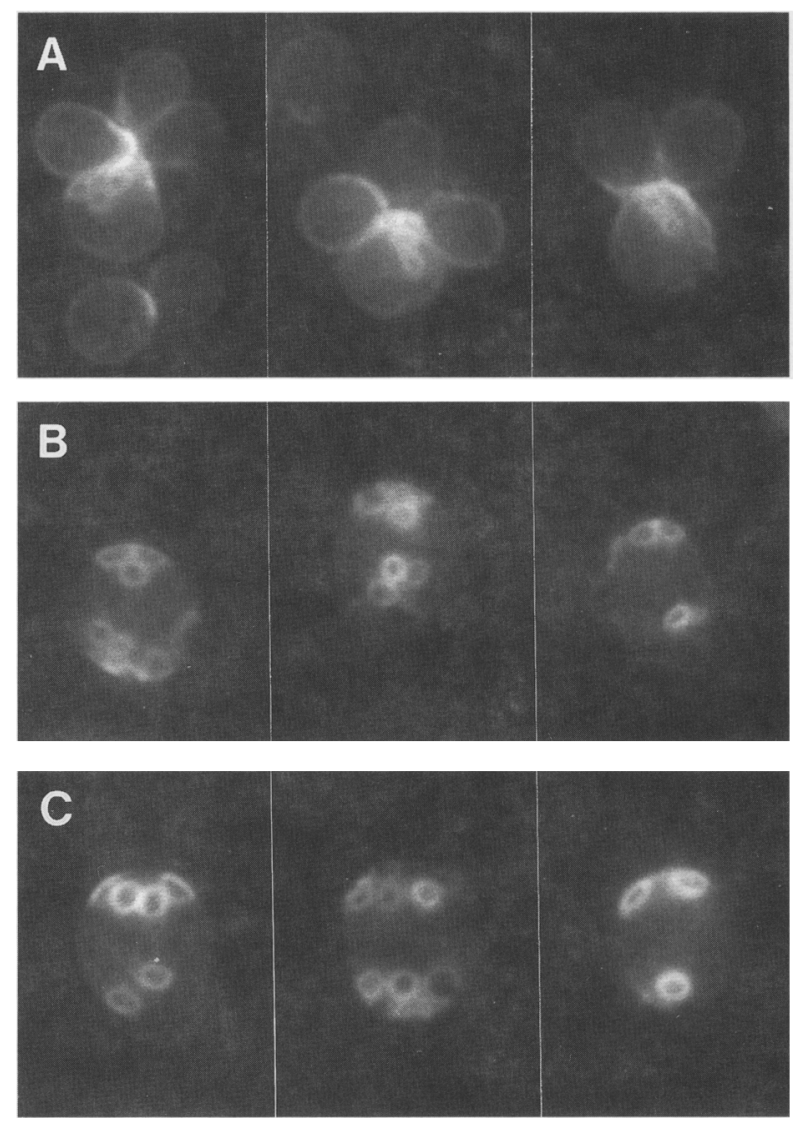

Figure 3. Bud scar distribution. Bud scars were stained and visualized for haploid MATa strain L5528 during exponential growth $(A)$ and invasive growth $(B)$, and for the isogenic diploid $M A T$ a/ $\alpha$ strain $L 5721$ during exponential growth $(C)$.

\section{Haploid bud site switching depends on BUD gene functions}

The products of five $B U D$ genes affect the position of bud site selection. $B U D 3$ and $B U D 4$ are required for the axial pattern of bud site selection in haploids; both bud3 and bud4 haploid strains exhibit bipolar budding (Table 4). Our analysis of the cells beneath the colony shows that both bud 3 and bud 4 haploids form filaments similar to those formed by $\mathrm{Bud}^{+}$strains (data not shown).

Table 2. Haploid bipolar budding

\begin{tabular}{lcccc}
\hline & \multicolumn{3}{c}{ Bud scar distribution } & \\
\cline { 2 - 4 } Sample & axial & bipolar & anomalous & $n$ \\
\hline MATa exponential & 98 & 1 & 1 & 500 \\
MATa below agar & 30 & 62 & 8 & 800 \\
MATa/ $\alpha$ exponential & 28 & 66 & 6 & 200 \\
\hline
\end{tabular}

The distribution of bud scars was scored for the haploid strain L5528 during exponential and invasive growth on plates, and for the diploid strain L5721 during exponential growth in liquid. Numbers represent the percentage of cells in each class (see Materials and methods) and the sample size (n). 
Table 3. Haploids do not switch budding patterns in liquid

\begin{tabular}{lcccc}
\hline & \multicolumn{3}{c}{ Bud scar distribution } & \\
\cline { 2 - 4 } Sample & axial & bipolar & anomalous & $n$ \\
\hline MATa exponential & 98 & 1.0 & 1.0 & 400 \\
MATa 2 days & 80 & 15 & 4.3 & 391 \\
MATa 20 days & 85 & 8.0 & 7.0 & 100 \\
\hline
\end{tabular}

The distribution of bud scars was scored for the haploid strain L5528 after growth in YPD liquid for various amounts of time. Numbers represent the percentage of cells in each class (see Materials and methods) and the sample size $(n)$.

Three gene products, $B U D 1, B U D 2$, and $B U D 5$, are required for both the axial and bipolar budding patterns. Haploid bud1, bud2, and bud5 mutant strains exhibit a random distribution of bud emergence sites on the cell surface. Unlike isogenic Bud ${ }^{+}$strains, these mutants do not switch to the bipolar budding pattern (Table 4) or form filaments in our plate assay (data not shown). Thus, a bipolar budding pattern is necessary for filament formation.

\section{Agar penetration does not require BUD gene functions}

Haploid bud1, bud2, and bud5 mutants fail to form filaments on rich medium, but they penetrate agar as well as Bud ${ }^{+}$strains (Fig. 4). Therefore, a polar mode of bud site selection is not necessary for agar penetration, although it is necessary for filament formation. To test whether $B U D$ genes are also required for diploid filamentous growth, we constructed diploid strains homozygous for a deletion of $B U D 1$. These strains bud randomly and fail to form filaments on plates (SLAD) that induce pseudohyphal growth in diploid Bud ${ }^{+}$strains, although they form normal proportions of long cells that penetrate the agar below each colony (data not shown). On rich medium used to observe haploid invasive growth (YPD), diploid $\mathrm{Bud}^{+}$strains do not penetrate agar efficiently (Figs. 1 and 4), although they exhibit the bipolar budding pattern necessary for filamentous growth. Taken together these data suggest that filament formation and agar penetration are distinct functions in both haploids and diploids. Thus, a polar mode of bud site selection is neither necessary nor sufficient for agar penetration; other factors must regulate this behavior.

\section{Elements of the pheromone response pathway are required for haploid invasive growth}

Because mutations in the mating signal transduction pathway block both the filament formation and the agar penetration of diploid strains, we reasoned that this pathway might control these behaviors in haploids as well. Haploid strains carrying deletions in various pheromone response pathway genes were tested for their ability to penetrate agar. Strikingly, the same components of the MAPK cascade necessary for diploid pseudohyphal growth are required for haploid invasive growth. As in diploids, the pheromone receptor (STE2) and the G protein (STE4, STE18) are not required for haploid agar penetration. Similarly, the scaffold protein $(S T E 5)$ that nucleates assembly of the signaling kinases is not required nor is the cyclin-dependent kinase inhibitor (FAR1) (Fig. 5; data not shown). In contrast, other components of the MAP kinase cascade, including STE20, STE11 (MEKK), STE7 (MEK), and the transcription factor STE12, are essential for agar penetration (Fig. 5). As in diploids (Liu et al. 1993), the ste20 mutant shows the strongest phenotype of all the mutants in this pathway. In each case, the defect in the invasive growth of these strains is completely linked to the ste deletion (Fig. 6), and agar penetration can be restored by introduction of the appropriate STE gene. It is difficult to assess whether the noninvasive ste mutants are completely defective in filament formation because our assay requires examination of the cells remaining in the agar. Nevertheless, the few cells that do remain after washing the plate do not appear to form filaments (data not shown). Therefore, we conclude that these mutant strains are defective in agar penetration and probably also filament formation.

\section{A MAPK is required for haploid invasive growth}

Haploid strains containing deletions of the Fus3p and Ksslp MAPK homologs were tested for their ability to

Table 4. The budding pattern switch requires BUD genes

\begin{tabular}{|c|c|c|c|c|c|c|}
\hline \multirow[b]{3}{*}{ Sample } & \multicolumn{6}{|c|}{ Bud scar distribution } \\
\hline & \multicolumn{3}{|c|}{ exponential growth } & \multicolumn{3}{|c|}{ invasive growth } \\
\hline & axial & bipolar & anomalous & axial & bipolar & anomalous \\
\hline $\mathrm{Bud}^{+}$ & 98 & 1.5 & 0.0 & 26 & 66 & 8.0 \\
\hline bud1 & 14 & 14 & 72 & 9.0 & 20 & 72 \\
\hline bud2 & 12 & 13 & 75 & 2.0 & 21 & 77 \\
\hline bud3 & 21 & 64 & 15 & 26 & 59 & 15 \\
\hline bud4 & 23 & 65 & 12 & 20 & 65 & 15 \\
\hline
\end{tabular}

The distribution of bud scars was scored for haploid strains (Bud ${ }^{+}$L5528), (bud1 L5726), (bud2 L5727), (bud3 L5725), and (bud4 F1432) during exponential growth in liquid and invasive growth on plates. Numbers represent the percentage of cells in each class (see Materials and methods) for a sample size of $n=200$. 


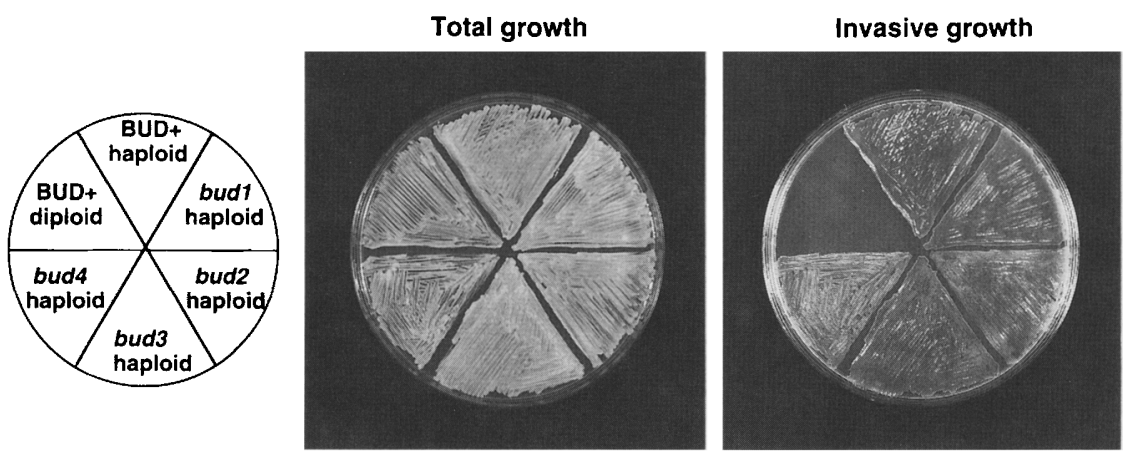

Figure 4. Haploid invasive growth and bud site selection. Haploid strains (Bud ${ }^{+}$ L5528), (bud1 L5726), (bud2 L5727), (bud3 L5725), (bud4 F1432), and the diploid $\left(\mathrm{Bud}^{+} / \mathrm{Bud}^{+} \mathrm{L} 5721\right)$ were patched on a YPD plate and incubated as described in Materials and methods. The plate was photographed before (total growth) and after (invasive growth) washing the cells off of the agar surface. penetrate agar. These genes are partially redundant for an essential mating function (Elion et al. 1991a,b) but are not required for filament formation in diploids (Liu et al. 1993). Haploid kss1 strains show greatly reduced agar penetration (Fig. 7), demonstrating that Ksslp promotes haploid invasive growth. In contrast, fus3 strains penetrate agar more vigorously than FUS3 strains, suggesting that Fus3p inhibits haploid invasive growth (Fig. 7). Surprisingly, the double mutant fus $3 \mathrm{kss} 1$ penetrates agar as well as the wild-type FUS3 KSS1 strain. Because the fus3 kss1 double mutant penetrates agar better than the kss1 single mutant, we hypothesized that there might be a novel MAPK, partially redundant with Ksslp, that is inhibited by the presence of a functional FUS3 gene. To test whether the enhanced agar penetration of the fus 3 mutant strain is dependent on a functional signal transduction pathway, we analyzed fus 3 ste 7 and fus 3 ste 12 mutants. These double mutant strains, like the ste 7 and ste12 single mutant strains, fail to penetrate agar (Fig. 7). We tested deletions of the MAPK homologs HOG1 and $M P K 1$ and found that these kinases do not play a role in agar penetration (data not shown). Taken together these data support a positive role for Ksslp in haploid invasive growth and raise the possiblity of a heretofore unidentified MAPK.

\section{STE pathway components are not required for bud site switching}

To determine whether the pheromone response MAP kinase pathway controls the bud site switching essential for haploid filament formation, we examined the pattern of bud site selection in ste strains. Because certain ste mutants penetrate agar poorly, we analyzed the budding pattern of cells collected from colonies on the agar surface. All the ste mutants in the pheromone response pathway still switch their budding pattern from an axial to a bipolar mode when grown for several days on YPD plates (Table 5). Although the proportion of cells that switch from axial to bipolar budding is not as great for the cells on the agar surface as for those below the surface (cf. Tables 2 and 5), it is clear that the ste mutants retain the capacity to switch to the bipolar pattern.

\section{Mating-specific transcription is not induced during haploid invasive growth}

Because haploid cells express all of the genes required for induction of pheromone-responsive genes, it is possible that mating-specific genes, such as FUS1, are activated in the cells under the colony during the induction of haploid invasive growth. To test this possibility, we compared the expression levels of a FUS1-lacZ construct in haploid cells that had penetrated the agar or were cultured in the presence of mating pheromone. This reporter provides a sensitive assessment of the transcriptional induction of mating-specific genes. Transcription of FUS1-lacZ is induced 100-fold during the pheromone response, and this induction is mediated by the transcription factor Ste12p (Dolan and Fields 1990; Hagen et al. 1991). Our data show that there is no induction of FUS1 in cells above or below the agar in the absence of mating pheromone (Table 6). Thus, the signaling cascade and the transcription factor Ste12p pre-
Total growth

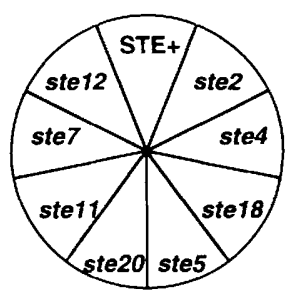

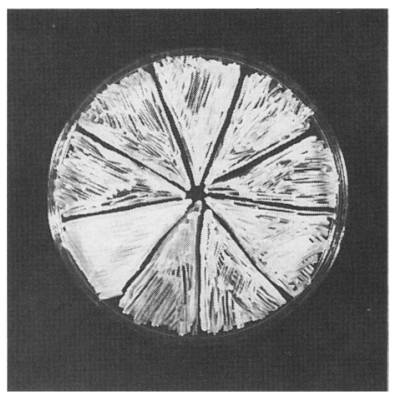

Invasive growth

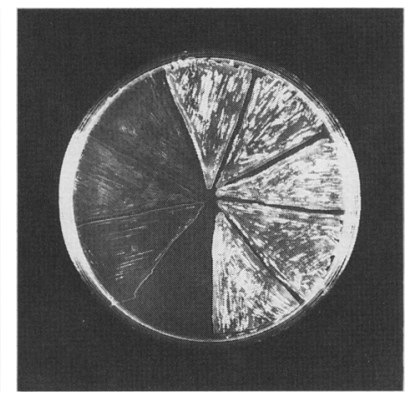

Figure 5. Elements of the pheromone response pathway are required for agar penetration. Haploid MATa strains (STE+ L5528), (ste2 L5466) (ste4 L5549), (ste18 L5579), (ste5 L5554), (ste20 L5585), (ste11 L5565), (ste7 L5559), and (ste12 L5573) were patched on a YPD plate and incubated as described in Materials and methods. The plate was photographed before (total growth) and after (invasive growth) washing the cells off of the agar surface. 

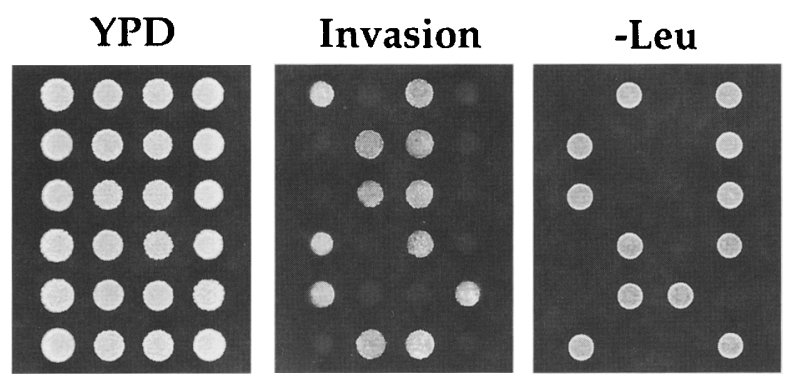

Figure 6. Invasive growth is linked to STE12. The diploid strain (ste12::LEU2/STE12, leu2/leu2 L5741) was sporulated and subjected to tetrad analysis. Spores were assayed for growth on YPD (total growth), agar penetration (invasive growth), and the ability to grow on medium lacking leucine (growth on - Leu).

sumably induce a set of genes specific to haploid invasive growth that is distinct from pheromone-inducible genes.

\section{Discussion}

\section{A comparison of haploid invasive growth and diploid pseudohyphal growth}

Haploid invasive growth is a developmental program with many similarities to diploid pseudohyphal growth. First, in both haploids and diploids, filament formation and agar penetration appear to be induced by nutrient limitation. Second, both cell types form filaments through a series of polarized cell divisions that depend on a polar pattern of bud site selection. Furthermore, filament formation is distinct from agar penetration in both cell types, as both haploid and diploid bud strains are unable to form filaments but still penetrate agar. Perhaps the most striking similarity is that elements of the pheromone response MAP kinase signal transduction pathway, including STE2O, STE11, STE7, and STE12, are required for triggering these developmental events in both haploids and diploids.

However, there are differences between haploid invasive growth and diploid pseudohyphal growth. Diploids form filaments readily on low ammonia medium, but poorly on rich medium. In contrast, haploids do not appear to form filaments on low ammonia medium, but do form them on rich medium. Moreover, diploid filaments extend beyond the perimeter of the colony, whereas haploid filaments are only observed beneath the colony. In addition, cells in diploid pseudohyphal filaments are more elongated than those in haploid filaments. Despite these differences, haploid invasive growth and diploid pseudohyphal growth share several common motifs and require many of the same genes, suggesting that they are different manifestations of a common developmental pathway.

\section{Haploid filamentous growth requires bud site switching}

Bud site selection is not a fixed parameter determined by cell type but, rather, a dynamic process sensitive to environmental influences. Haploid cells switch from an axial to a bipolar mode of bud site selection when grown on rich medium for an extended period. In the bipolar mode, the first bud emerges from the free end of the cell, but subsequent buds can emerge from either end. Diploid cells switch from a bipolar to a unipolar budding pattern when starved for nitrogen (Kron et al. 1994). In the unipolar budding pattern, the first bud and all subsequent buds emerge from the free end of the cell. Thus, upon nutrient deprivation, both diploid and haploid cells switch their pattern of bud site selection and form filaments.

The polar budding pattern provides the architectural motif for the growth and extension of a filament. In polar budding the first bud of each virgin mother emerges from the free end of the cell, away from her mother. The switch in diploids from bipolar to unipolar budding ensures that all new growth projects in filaments away from the colony. The switch in haploids from axial to bipolar budding is also consistent with filament formation. Both the bipolar chain and the unipolar chain are composed of a lineage of buds born from the free end of each new cell in the chain. However, in the bipolar pattern the emergence of subsequent buds on the birth end of cells can lead to secondary fronds projecting back toward the cell that originated the chain. This difference may explain why the haploid filaments we observe are

\begin{abstract}
Figure 7. The role of MAPKs in haploid agar invasion. Haploid strains (STE $^{+}$ L5528), (fus3 L5479), (kss1 L5491), (fus3 kss1 L5722), (ste7 L5559), (fus3 ste7 L5723), (ste12 L5573), and (fus3 ste12 L5724) were patched on a YPD plate and incubated as described in Materials and methods. The plate was photographed before (total growth) and after (invasive growth) washing the cells off of the agar surface.
\end{abstract}

\section{Total growth}

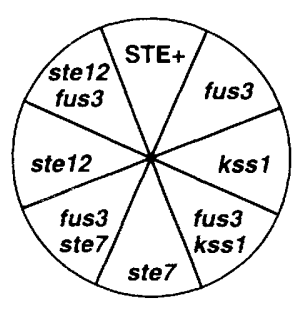

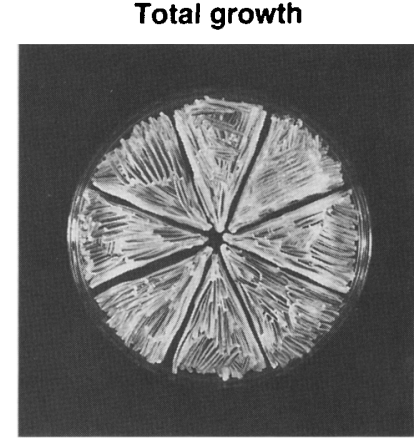

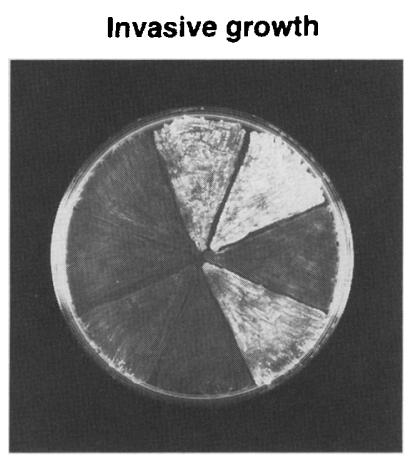


Table 5. Bud site switching does not require STE genes

\begin{tabular}{lccc}
\hline & \multicolumn{3}{c}{ Bud scar distribution } \\
\cline { 2 - 4 } Sample & axial & bipolar & anomalous \\
\hline Ste $^{+}$ & 53 & 42 & 5 \\
ste2 & 45 & 46 & 9 \\
ste4 & 43 & 50 & 7 \\
ste18 & 45 & 47 & 8 \\
ste20 & 46 & 48 & 6 \\
ste5 & 43 & 53 & 4 \\
ste11 & 59 & 37 & 4 \\
ste7 & 51 & 43 & 6 \\
fus3 & 46 & 50 & 4 \\
kss1 & 50 & 42 & 8 \\
fus3, $k$ ss1 & 46 & 48 & 8 \\
ste12 & 50 & 42 & 8 \\
\hline
\end{tabular}

The distribution of bud scars was scored for haploid MATa strains (Ste ${ }^{+}$L5528), (ste2 L5466), (ste4 L5549), (ste18 L5579), (ste20 L5585), (ste5 L5554), (ste11 L5565), (ste7 L5559), (fus3 L5479), (kss1 L5491), (fus3 kss1 L5722), and (ste12 L5573) after 5 days of growth on a YPD plate. Numbers represent the percentage of cells in each class (see Materials and methods) for a sample size of $n=200$.

not as extensive or ordered as pseudohyphal filaments. Mutations in BUD1, BUD2 and BUD5 disrupt the polar budding pattern and consequently block filament formation. Thus, reiteration of the polar budding pattern is a critical element of filament formation.

\section{Filament formation is distinct from agar penetration}

Filament formation can be dissected genetically from agar penetration and cell elongation. Haploid bud1, bud2, and bud5 mutants penetrate agar as efficiently as $\mathrm{Bud}^{+}$strains, even though these mutants do not form ordered filaments. Similarly, diploid bud1/bud1 mutants penetrate agar and form clusters of long cells on medium that induces pseudohyphal growth, although they too fail to form filaments. Thus, the pattern of bud site selection determines the ability of a strain to form ordered filaments but does not affect agar penetration or cell elongation. Mutations in the STE20, STE11, STE7, and $S T E 12$ genes block agar penetration and filamentous growth in both haploid and diploid cells, but do not affect bud site switching in haploid cells. Filament formation and agar penetration depend on signaling through elements of this MAP kinase cascade, but each process is ultimately controlled by distinct downstream morphological pathways.

\section{MAP kinase pathway components control haploid invasive growth}

We report here that three protein kinases of the mating pheromone response MAP kinase cascade, Ste20p, Stellp (MEKK), and Ste7p (MEK) and the transcription factor Ste12p, are required for haploid invasive growth. These same components are required for pseudohyphal growth in diploid cells (Liu et al. 1993). The mating pheromone receptors and the $G$ protein, which transmit the primary signal in the pheromone response, are not required for either haploid invasive growth or diploid pseudohyphal growth. It is significant that the pheromone receptors and $G$ protein are not required for haploid invasive growth, because the genes encoding these proteins are transcribed and the proteins are functional in haploids, whereas they are not in diploids (Whiteway et al. 1989; Liu et al. 1993). The mating pheromone response MAPK signal transduction pathway may be key to filamentous growth in all fungi. In the human pathogen Candida albicans, the STE12 homolog CPH1 plays a role in hyphal formation (Liu et al. 1994). In Ustilago maydis, the STE7 homolog Fuz7 is required for mating functions, filamentous growth, and pathogenesis (Banuett and Herskowitz 1994). Unlike Saccharomyces, Ustilago pheromones and their receptors, encoded by the $a$ locus, also play a role in filamentous growth (Bolker et al. 1992).

\section{The role of MAPKs in haploid invasive growth}

The FUS3 and KSS1 MAPKs are partially redundant for an essential function in the haploid pheromone response (Elion et al. 1991a,b). The single mutants are fertile, but the fus 3 kss 1 double mutant is completely sterile. The FUS3 kss1 single mutant is defective in agar penetration, whereas the fus 3 KSS1 mutant is enhanced. The role of the FUS3 and KSS1 genes in haploid invasive growth is unexpected because these genes are not required for diploid pseudohyphal growth. Formally, Ksslp plays a positive role in haploid invasive growth and Fus3p plays a negative role. Epistasis analysis shows that the enhanced agar penetration of the fus 3 mutant depends on the function of two other components of this pathway, STE7 and STE12.

These data raise the possibility that Ksslp may be partially redundant with a novel MAPK in the invasive growth signaling pathway; either can activate Ste12p to promote invasive growth. The presence of Fus $3 p$ might interfere with the function of the postulated MAPK,

Table 6. FUS1-lacZ is not induced during haploid invasive growth

\begin{tabular}{lc}
\hline \multicolumn{2}{c}{ Mating transcription induction } \\
\hline \multicolumn{1}{c}{ sample } & $\beta$-galactosidase activity \\
\hline MATa exponential growth $+\alpha \mathrm{F}$ & 250 \\
MATa exponential growth & 2.2 \\
MATa on agar surface & 0.40 \\
MATa beneath agar surface & 0.39 \\
\hline
\end{tabular}

$\beta$-Galactosidase activity was assayed in cells of the haploid MATa strain L5728 during exponential growth in YPD liquid in the presence and absence of mating pheromone, and after 5 days of growth on a YPD plate. Numbers represent $\beta$-galactosidase activity normalized to total protein (see Materials and methods). 
thereby reducing the invasive growth signal. This model explains the strength of the haploid invasion phenotypes that we observe: strongest in fus $3 \mathrm{KSS1}$, intermediate in FUS3 KSS1 and fus 3 kss1, and weakest in FUS3 kss1. The postulated MAPK is unlikely to be either MPK1 or HOG1, two other MAPKs present in yeast, because deletions of these genes do not block haploid invasive growth. Alternatively, there may not be a third MAPK involved in haploid invasive growth. Instead, Ksslp could promote, and Fus $3 p$ antagonize, the Ste $7 p$-dependent Ste $12 p$ activation required for haploid invasive growth.

Elements of a single MAP kinase pathway control two developmental events in the same cell type

Our finding that components of the pheromone response signal transduction pathway are required for both mating and haploid invasive growth demonstrates that a single MAP kinase cascade can specify two different developmental outcomes in a haploid cell. The target of this cascade, the transcription factor Ste12p, is required for both processes, presumably to regulate the expression of genes specific to each developmental program. Because mating-specific genes are not induced detectably during haploid invasive growth, Ste $12 p$ must have at least two functional states: one that controls the transcription of mating-specific genes, and another that controls the transcription of genes specific to haploid invasive growth. Each Ste12p state might have a distinct phosphorylation pattern that determines DNA-binding specificity, association with other transcription factors, or both.

How do haploid cells distinguish between two different stimuli that activate the same signal transduction pathway and initiate the developmental program specific to each primary signal? In one model, accessory proteins are activated that direct the association of common components of the pathway with their appropriate targets (Fig. 8). For example, in the response to mating pheromone, Ste $5 p$ assembles Ste11p, Ste7p, and Fus3p into a protein complex that modifies Ste12p, shifting it to a state that activates the transcription of mating-specific genes (Choi et al. 1994; Kranz et al. 1994; Marcus et al. 1994). According to this model, upon induction of the haploid invasive growth pathway, a scaffolding protein analogous to Ste5p mediates the assembly of Stellp and Ste7p with a MAPK distinct from Fus3p. The protein complex modifies Ste12p, shifting it to a state that activates the transcription of genes specific to haploid invasive growth (Fig. 8). This explains why the pheromone receptors, G protein, FUS3, and STE5 are not necessary for haploid invasive growth, whereas STE20, STE7, STE11, and STE12 are essential. Other models that do not require a MAPK are consistent with these data.

\section{A paradigm for generating diversity from a signal transduction pathway}

Our observation that elements of a single MAP kinase

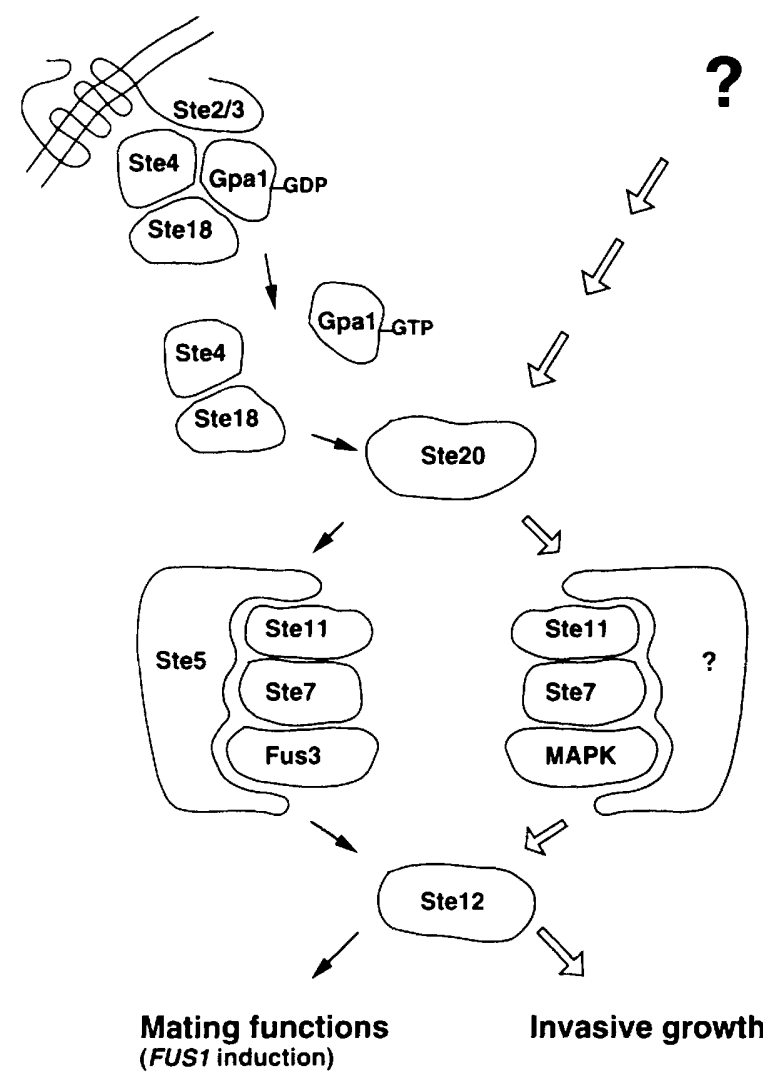

Figure 8. A single MAP kinase cascade controls two developmental events in a haploid yeast cell: mating and invasive growth.

pathway control two distinct developmental sequences could emerge as a general theme. MAP kinase pathways have been implicated in development and differentiation in many organisms. In mammalian cells, a wide array of growth factors and cytokines can activate a MAP/ERK kinase cascade that stimulates proliferation or differentiation (Blumer and Johnson 1994). In D. melanogaster, a dominant activated allele of a single MAPK gene disrupts the development of several tissues (Brunner et al. 1994); although in this case, each of these processes occurs in distinct cell types at different times during development.

There are precedents for two distinct signals acting through a single MAP kinase pathway in the same cell type. For example, in cardiac myocytes both endothelin (ET-1) and acidic fibroblast growth factor (aFGF) activate a MAPK, and induce hypertrophy in these cells (Bogoyevitch et al. 1994). ET-1 acts through G proteincoupled serpentine receptors and phospholipase $C \beta$, whereas aFGF activation is mediated by a family of tyrosine kinase receptors. These two agonists act through disparate primary signaling events, but both pathways converge on the MAPK to mediate the same physiologic response. Perhaps the closest parallel to the dual functionality of the MAP kinase pathway in $S$. cerevisiae is the behavior of $\mathrm{PC} 12$ cells in response to epidermal 
growth factor (EGF) and nerve growth factor (NGF) (Traverse et al. 1992). EGF induces transient ERK/MAPK activation and cell division in these cells. In contrast, NGF induces prolonged activation and nuclear translocation of ERK/MAPK, causing the same cells to arrest growth and initiate neuronal differentiation. The molecular sequence of events underlying this differential MAPK activation has not yet been determined. Identification of the primary signals and the putative novel MAPK required for yeast filamentous growth should help to elucidate the mechanism for achieving diversity from a single cascade.

\section{Materials and methods \\ Strains and growth conditions}

All yeast strains used in this study are described in Table 1 and are congenic to the $\Sigma 1278 \mathrm{~b}$ genetic background (Grenson et al. 1966; Liu et al. 1993). Standard yeast culture medium was prepared essentially as described (Sherman et al. 1986). YPD plates [2\% yeast extract (Difco), 4\% Bacto peptone (Difco), 2\% glucose, $2 \%$ Bacto-agar (Difco), and $0.03 \%$ L-tryptophan) were allowed to cool, polymerize, and dry for 3 days at room temperature before use. Low ammonia medium (SLAD) for scoring pseudohyphal growth was prepared as described /Gimeno and Fink 1994). Strains scored for pseudohyphal filament formation were streaked on SLAD plates and observed after 24,48 , and 72 hr of growth at $30^{\circ} \mathrm{C}$. Long cells that had penetrated the agar were examined after washing the cells off of the agar surface with deionized water.

Cells in exponential growth phase in liquid were prepared by incubating cells in YPD medium on a roller drum at $30^{\circ} \mathrm{C}$ until the culture reached an $\mathrm{OD}_{600}$ of 0.6 . Cells in exponential growth phase on plates were prepared by plating $3 \mathrm{ml}$ of cells at an $\mathrm{OD}_{600}$ of 0.6 (see above) on a YPD plate and incubating them for an additional $8-10 \mathrm{hr}$ at $30^{\circ} \mathrm{C}$.

\section{Invasive growth assay}

Strains were patched on YPD plates with a toothpick, with care being taken to avoid scratching the agar surface. Patches were allowed to grow at $30^{\circ} \mathrm{C}$ for 3 days and incubated at room temperature for an additional 2 days. For tetrad analysis, haploid cells were transferred from liquid cultures in a microtiter dish to a YPD plate. Because these samples started at a higher cell density than the patches described previously, invasive growth was scored after 2 days of growth at $30^{\circ} \mathrm{C}$. Samples were photographed with a $35 \mathrm{~mm}$ camera using Technical Pan (Kodak) film, and a gentle stream of deionized water was then used to rinse all the cells from the agar surface. The agar was never rubbed directly or otherwise disrupted. Microscopic analysis revealed that the cells remaining after washing were below the focal plane of the agar surface and inaccessible to a microdissection needle unless the needle pierced the agar. Plates were allowed to dry briefly and were then photographed again as described above. Cells that had penetrated the agar were excised with a toothpick for subsequent manipulations.

Filament formation was scored after 2 days of invasive growth at $30^{\circ} \mathrm{C}$ because the number of cells in the agar after 5 days was too high to distinguish individual filaments. Cells remaining in the agar after washing the plate were overlayed with a coverslip and scored by direct microscopic examination for the presence of filaments. For the purpose of this study, a filament is defined as a chain of cells attached to one another that projects in an ordered pattern away from the first cell of the chain.

\section{Photomicroscopy}

Preparations of cells in exponential growth were prepared as described above, placed on a slide with a coverslip, and compressed gently to ensure that all the cells in each clump were in the same focal plane. Cells undergoing invasive growth were cultured as described above and prepared for observation by excising the washed agar from the plate and placing it between two coverslips. Samples were viewed with Nomarski optics on a Zeiss Axioscop and photographed with a $35 \mathrm{~mm}$ camera using Technical Pan (Kodak) film. To determine the axial ratio of cells, we prepared samples and photographed them as described above. Images were printed onto photographic paper and directly measured. The length was measured along the longest axis of each cell, and the width was measured at the midpoint of the longest axis (Gimeno et al. 1992). The mean length/width ratios are presented for each sample along with the standard error of the mean.

\section{Bud scar staining}

Invasive cells were prepared as described above and excised from washed plates with a toothpick. Cells in exponential growth phase were prepared as described above. Samples were forced through a 24-gauge needle 10 times to separate cells as much as possible and rinsed in water once before fixation. Cell suspensions were fixed at room temperature for $2 \mathrm{hr}$ in $3.7 \%$ formaldehyde. Samples were rinsed twice in water and resuspended in $200 \mu \mathrm{l}$ of a fresh stock of $1 \mathrm{mg} / \mathrm{ml}$ of calcofluor white (Fluorescent Brightener no. 28 F6259, Sigma) in water. Samples were stained at room temperature in the dark for $10 \mathrm{~min}$ and washed three times in water before observation.

Bud scars were visualized by fluorescence microscopy on a Zeiss Axioscop, and photographed with a $35 \mathrm{~mm}$ camera using TMAX 400 (Kodak). Cells with 2-10 clear bud scars were divided into three bud scar distribution classes: axial, cells with all bud scars at one end of the cell immediately adjacent to one another; bipolar, cells with two or more bud scars with at least one scar at each end of the cell (the birth end and the free end); anomalous, cells with bud scar distributions other than axial or bipolar. Numbers in the tables represent the percent of cells in each class for a sample of $n$ cells.

\section{Time-lapse photomicroscopy}

A plate of invading cells was prepared as described above, and a coverslip was placed over the cells remaining in the agar. Each plate was taped down on a Zeiss WL light microscope stage, maintained at $30^{\circ} \mathrm{C}$, and photographed at 90-min intervals over a 14-hr period with a $35 \mathrm{~mm}$ camera using Technical Pan film (Kodak). Budding was observed and classified according to the site where the first bud of a virgin mother emerged. None of the cells present on the plate at time zero was scored, as their birth end could not always be determined. Instead, buds that emerged after the first time point and subsequently initiated buds of their own were defined as virgin mothers. The birth end of a virgin mother was defined as the region adjacent to the site where she was attached to her mother, and the free end was defined as the end of the cell opposite the birth end (Freifelder 1960). The position of bud site emergence of these virgin mothers was determined by direct microscopic observation.

Exponential growth samples were prepared as described above and subjected to time-lapse analysis. In these preparations we 
find that mother and daughter cells remain attached to one another even after being subjected to high shear forces. This site of attachment defines the birth end of each cell (Freifelder 1960). However, because the majority of these cells are in large clumps, we could not always identify the first bud of a virgin mother and simply scored new buds as emerging from the free end or the birth end of the cell.

\section{$\beta$-Galactosidase assays}

$\beta$-Galactosidase assays were performed essentially as described (Trueheart et al. 1987). Exponential growth phase samples were prepared as described above and split into two samples. These samples were spun, resuspended in $5 \mathrm{ml}$ of $\mathrm{YPD}(\mathrm{pH} \mathrm{4)}$ with or without $5 \mu \mathrm{M} \alpha$-factor, and incubated at $30^{\circ} \mathrm{C}$ for an additional $2 \mathrm{hr}$ before being harvested. Cells undergoing invasive growth were prepared as described above. Before washing the plate, cells on the agar surface were gently scraped away and harvested. Separate plates grown under the same conditions were washed as described, and the cells excised from the agar were harvested. All cells were washed with water once before being lysed to remove contaminating protein. $\beta$-Galactosidase activity was normalized to the total protein in each extract according to the equation: $\left(O D_{420} \times 1.7\right) /(0.0045 \times \mathrm{mg} / \mathrm{ml}$ protein $\times$ extract volume $\times$ timel.

\section{Acknowledgments}

We thank John Chant and Alan Bender for graciously providing the plasmids to delete $B U D$ genes. We thank Haoping Liu for providing many useful strains. We also thank Judith Bender, Bonnie Bartel, Kyle Cunningham, Peter Hecht, Steve Kron, and Samantha Roberts for helpful discussions and comments on the manuscript. This work was supported by Bristol Myers Squibb and National Institutes of Health grants GM-40266 and AI-07348. G.R.F. is an American Cancer Society Professor of Genetics.

The publication costs of this article were defrayed in part by payment of page charges. This article must therefore be hereby marked "advertisement" in accordance with 18 USC section 1734 solely to indicate this fact.

\section{References}

Banuett, F. and I. Herskowitz. 1994. Identification of Fuz7, a Ustilago maydis MEK/MAPKK homolog required for $a$-locus-dependent and -independent steps in the fungal life cycle. Genes \& Dev. 8: 1367-1378.

Bender, A. and J.R. Pringle. 1989. Multicopy suppression of the cdc2 4 budding defect in yeast by CDC42 and three newly identified genes including the ras-related gene RSR1. Proc. Natl. Acad. Sci. 86: 9976-9980.

Blumer, K.J. and G.L. Johnson. 1994. Diversity in function and regulation of MAP kinase pathways. Trends Biochem. Sci. 19: $236-240$.

Bogoyevitch, M.A., P.E. Glennon, M.B. Andersson, A. Clerk, A. Lazou, C.J. Marshall, P.J. Parker, and P.H. Sugden. 1994. Endothelin-1 and fibroblast growth factors stimulate the mitogen-activated protein kinase signaling cascade in cardiac myocytes. The potential role of the cascade in the integration of two signaling pathways leading to myocyte hypertrophy. I. Biol. Chem. 269: 1110-1119.

Bolker, M., M. Urban, and R. Kahmann. 1992. The a mating type locus of U. maydis specifies cell signaling components. Cell 68: $441-450$,
Brewster, J.L., T. de Valoir, N.D. Dwyer, E. Winter, and M.C. Gustin. 1993. An osmosensing signal transduction pathway in yeast. Science 259: 1760-1763.

Brunner, D., N. Oellers, J. Szabad, W.H. Biggs III, S.L. Zipursky, and E. Hafen. 1994. A gain-of-function mutation in Drosophila MAP kinase activates multiple receptor tyrosine $\mathrm{ki}$ nase signaling pathways. Cell 76: 875-888.

Cairns, B.R., S.W. Ramer, and R.D. Kornberg. 1992. Order of action of components in the yeast pheromone response pathway revealed with a dominant allele of the STE11 kinase and the multiple phosphorylation of the STE7 kinase. Genes \& Dev. 6: 1305-1318.

Chang, F. and I. Herskowitz. 1990. Identification of a gene necessary for cell cycle arrest by a negative growth factor of yeast: FAR1 is an inhibitor of a G1 cyclin, CLN2. Cell 63: 999-1011.

Chant, J. and I. Herskowitz. 1991. Genetic control of bud site selection in yeast by a set of gene products that constitute a morphogenetic pathway. Cell 65: 1203-1212.

Choi, K., B. Satterberg, D.M. Lyons, and E.A. Elion. 1994. Ste5 tethers multiple protein kinases in the MAP kinase cascade required for mating in S. cerevisiae. Cell 78: 499-512.

Ciriacy, M., K. Freidel, and C. Lohning. 1991. Characterization of trans-acting mutations affecting $\mathrm{Ty}$ and Ty-mediated transcription in Saccharomyces cerevisiae. Curr. Genet. 20: $441-448$.

Crews, C.M., A. Alessandrini, and R.L. Erikson. 1992. The primary structure of $\mathrm{MEK}$, a protein kinase that phosphorylates the ERK gene product. Science 258: 478-480.

Dietzel, C. and J. Kurjan. 1987. The yeast SCG1 gene: A G $\alpha$-like protein implicated in the a- and $\alpha$-factor response pathway. Cell 50: 1001-1010.

Dolan, J.W. and S. Fields. 1990. Overproduction of the yeast STE12 protein leads to constitutive transcriptional induction. Genes \& Dev. 4: 492-502.

Elion, E.A., J.A. Brill, and G.R. Fink. 1991a. Functional redundancy in the yeast cell cycle: FUS3 and KSS1 have both overlapping and unique functions. Cold Spring Harbor Symp. Quant. Biol. 56: 41-49.

- $1991 \mathrm{~b}$. FUS3 represses CLN1 and CLN2 and in concert with KSSl promotes signal transduction. Proc. Natl. Acad. Sci. 88: 9392-9396.

Elion, E.A., B. Satterberg, and J.E. Kranz. 1993. FUS3 phosphorylates multiple components of the mating signal transduction cascade: Evidence for STE12 and FARI. Mol. Biol. Cell 4: 495-510.

Foster, D.A. 1993. Intracellular signalling mediated by proteintyrosine kinases: Networking through phospholipid metabolism. Cell Signal 5: 389-399.

Freifelder, D. 1960. Bud position in Saccharomyces cerevisiae. J. Bacteriology 80: 567-568.

Gartner, A., K. Nasmyth, and G. Ammerer. 1992. Signal transduction in Saccharomyces cerevisiae requires tyrosine and threonine phosphorylation of FUS3 and KSS1. Genes \& Dev. 6: 1280-1292.

Gimeno, C.J. and G.R. Fink. 1992. The logic of cell division in the life cycle of yeast. Science 257: 626 .

- 1994 . Induction of pseudohyphal growth by overexpression of PHD1, a Saccharomyces cerevisiae gene related to transcriptional regulators of fungal development. Mol. Cell. Biol. 14: 2100-2112.

Gimeno, C.J., P.O. Ljungdahl, C.A. Styles, and G.R. Fink. 1992. Unipolar cell divisions in the yeast $S$. cerevisiae lead to filamentous growth: Regulation by starvation and RAS. Cell 68: $1077-1090$.

Grenson, M., M. Mousset, J.M. Wiame, and J. Bechet. 1966. 
Multiplicity of the amino acid permeases in S. cerevisiae. Biochim. Biophys. Acta 127: 325-338.

Hagen, D.C., G. McCaffrey, and G. Sprague Jr. 1991. Pheromone response elements are necessary and sufficient for basal and pheromone-induced transcription of the FUSl gene of Saccharomyces cerevisiae. Mol. Cell. Biol. 11: 2952-2961.

Kranz, J.E., B. Satterberg, and E.A. Elion. 1994. The MAP kinase Fus3 associates with and phosphorylates the upstream signaling component Ste5. Genes \& Dev. 8: 313-327.

Kron, S., C.A. Styles, and G.R. Fink. 1994. Symmetric cell division in pseudohyphae of the yeast Saccharomyces cerevisiae. Mol. Biol. Cell. 5: 1003-1022.

Kyriakis, J.M., H. App, X.F. Zhang, P. Baneriee, D.L. Brautigan, U.R. Rapp, and I. Avruch. 1992. Raf-1 activates MAP kinasekinase. Nature 358: 417-421.

Lackner, M.R., K. Kornfeld, L.M. Miller, H.R. Horvitz, and S.K. Kim. 1994. A MAP kinase homolog, $m p k-1$, is involved in ras-mediated induction of vulval cell fates in Caenorhabdi. tis elegans. Genes \& Dev. 8: 160-173.

Lange-Carter, C.A., C.M. Pleiman, A.M. Gardner, K.J. Blumer, and G.L. Johnson. 1993. A divergence in the MAP kinase regulatory network defined by MEK kinase and Raf. Science 260: 315-319.

Leberer, E., D. Dignard, D. Harcus, D.Y. Thomas, and M. Whiteway. 1992. The protein kinase homologue Ste20p is required to link the yeast pheromone response $\mathrm{G}$ protein $\beta \gamma$ subunits to downstream signaling components. EMBO J. 11: 48154824.

Liu, H., C.A. Styles, and G.R. Fink. 1993. Elements of the yeast pheromone response pathway required for filamentous growth of diploids. Science 262: 1741-1744.

Liu, H., J. Koehler, and G.R. Fink. 1994. Suppression of hyphal formation in Candida albicans by mutation of a STE12 homolog. Science (in press).

Marcus, S., A. Polverino, M. Barr, and M. Wigler. 1994. Complexes between STE5 and components of the pheromoneresponsive mitogen-activated protein kinase module. Proc. Natl. Acad. Sci. 91: 7762-7766.

Pazin, M.J. and L.T. Williams. 1992. Triggering signaling cascades by receptor tyrosine kinases. Trends Biochem. Sci. 17: 374-378.

Ramer, S.W. and R.W. Davis. 1993. A dominant truncation allele identifies a gene, STE20, that encodes a putative protein kinase necessary for mating in Saccharomyces cerevisiae. Proc. Natl. Acad. Sci. 90: 452-456.

Rhodes, N., L. Connell, and B. Errede. 1990. Stell is a protein kinase required for cell-type-specific transcription and signal transduction in yeast. Genes \& Dev. 4: 1862-1874.

Schlessinger, J. and A. Ullrich. 1992. Growth factor signaling by receptor tyrosine kinases. Neuron 9: 383-391.

Sherman, F., G.R. Fink, and J. Hicks. 1986. Methods in yeast genetics. Cold Spring Harbor Laboratory, Cold Spring Harbor, New York.

Stevenson, B.J., N. Rhodes, B. Errede, G.F. Sprague Jr. 1992. Constitutive mutants of the protein kinase STE11 activate the yeast pheromone response pathway in the absence of the G protein. Genes \& Dev. 6: 1293-1304.

Traverse, S., N. Gomez, H. Paterson, C. Marshall, and P. Cohen. 1992. Sustained activation of the mitogen-activated protein (MAP) kinase cascade may be required for differentiation of PC12 cells. Comparison of the effects of nerve growth factor and epidermal growth factor. Biochem. J. 288: 351-355.

Trueheart, J., J.D. Boeke, and G.R. Fink. 1987. Two genes required for cell fusion during yeast conjugation: Evidence for a pheromone-induced surface protein. Mol. Cell. Biol. 7: 2316-2328.
Van Arsdell, S.W., G.L. Stetler, and J. Thomer. 1987. The yeast repeated element sigma contains a hormone-inducible promoter. Mol. Cell. Bio. 7: 749-759.

Whiteway, M., L. Hougan, D. Dignard, D.Y. Thomas, L. Bell, G.C. Saari, F.J. Grant, P. O'Hara, and V.L. Mac Kay. 1989. The STE 4 and STE 18 genes of yeast encode potential beta and gamma subunits of the mating factor receptor-coupled G protein. Cell 56: 467-477.

Wu, Y. and M. Han. 1994. Suppression of activated Let-60 ras protein defines a role of Caenorhabditis elegans Sur-1 MAP kinase in vulval differentiation. Genes \& Dev. 8: 147-159.

Zhou, Z., A. Gartner, R. Cade, G. Ammerer, and B. Errede. 1993. Pheromone-induced signal transduction in Saccharomyces cerevisiae requires the sequential function of three protein kinases. Mol. Cell. Biol. 13: 2069-2080. 


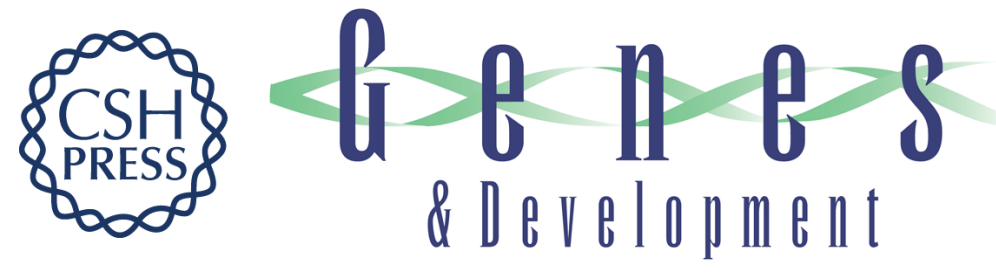

\section{Elements of a single MAP kinase cascade in Saccharomyces cerevisiae mediate two developmental programs in the same cell type: mating and invasive growth.}

R L Roberts and G R Fink

Genes Dev. 1994, 8:

Access the most recent version at doi:10.1101/gad.8.24.2974

References This article cites 45 articles, 29 of which can be accessed free at:

http://genesdev.cshlp.org/content/8/24/2974.full.html\#ref-list-1

License

Email Alerting Receive free email alerts when new articles cite this article - sign up in the box at the top Service right corner of the article or click here.

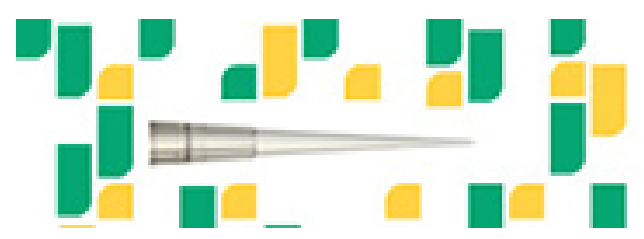

Focused on your science. 